\title{
Fuga de cerebros y biografías low cost: nueva etapa en la precarización de la juventud
}

\author{
Brain drain and low cost biographies: the new era \\ in the precarization of youth
}

ANTONIO SANTOS ORTEGA / DAVID MUÑOZ RODRÍGUEZ

Dpt. De Sociología y antropología social de la Universitat de ValÈnCia

Artículo recibido: 5 junio 2014

Solicitud de revisión: 30 noviembre 2014

Artículo aceptado: 13 enero 2015

Resumen

La normalización de la precariedad entre las personas jóvenes está entrando en lo que parece una nueva fase. De la mano de, entre otros factores, los discursos empresariales y la teoría del capital humano, estamos asistiendo a una vuelta de tuerca en la presión sobre la juventud: ya no basta con la búsqueda «activa» de empleo, ahora hay que invertir en uno mismo como «empresario de sí mismo» y, en esta lógica, si es preciso hay que optar por la «movilidad internacional». Presentamos una revisión teórica y conceptual alrededor de lo que se conoce como fuga de cerebros y su justificación discursiva. Estamos ante un proceso que probablemente dejará una marca importante en una generación que ha visto truncadas sus posibilidades de transición a situaciones estables, idealmente identificadas con el mundo adulto.

Palabras clave: Fuga de cerebros, juventud, precariedad, mercado de trabajo, capital humano.

\section{Abstract}

Normalization of precariousness among young people is entering in a new phase. Led by, among other factors, the human capital theory, we are witnessing a twist in pressure on young people: it is no longer enough with «active» job search, now you have to invest in yourself as entrepreneur of yourself' and in this logic, maybe young people must choose for the «international mobility», which is represented as a cosmopolitan option. We present a theoretical and conceptual review around what is known as brain drain and its discursive justification. We are facing a process that will probably leave a significant mark on a generation whose chances of transition to stable situations have been truncated, ideally identified with the adult world.

Keywords: Brain drain, youth, precariousness, labour market, human capital 


\section{INTRODUCCIÓN}

Mucho se ha hablado sobre la fuga de cerebros en estos últimos años. Desde el arranque de la crisis en 2007, el desplome progresivo de las expectativas laborales de la juventud empezó a ofrecer imágenes de jóvenes universitarios que emigraban en busca de empleo a diversos destinos en el extranjero. Los medios de comunicación amplificaron estos hechos reproduciendo entrevistas y testimonios de jóvenes donde se condensaba una frustración profunda. Frustración por sus absurdos recorridos educativos que les llevaban ahora a una vía muerta en España; frustración hacia un sistema político, que sentían como vergonzante por la corrupción y el mal gobierno; hacia un mundo empresarial y laboral, que creaba pocos espacios para el empleo cualificado; frustración por tener que marcharse a la fuerza de su país. Los reportajes periodísticos mostraban a unos jóvenes que trataban de afrontar la incertidumbre con pocos recursos, sin información, sin ayudas públicas. Una individualización absoluta, cuya única estrategia consistía, mayoritariamente, en buscarse la vida forzados por las circunstancias. Los jóvenes, sin embargo, mostraban siempre buen ánimo y pensamiento positivo, incluso cuando se daban cuenta de que transcurría el tiempo y no encontraban el empleo cualificado anhelado. En esta desbandada, algunos encontraron una oportunidad en las ciudades de destino. Otros, es difícil de cuantificar, cerraron su recorrido migratorio con un retorno frustrante a España tras meses de trabajo en empleos descualificados. Estos retornos son ya una realidad, pero los medios de comunicación no encuentran suficiente atractivo informativo en relatar estas trayectorias malogradas.

En todo caso, el denominador común de unos y otros recorridos es el alto grado de incertidumbre e individualización que los han caracterizado. Sea cual sea el resultado final para quien las protagoniza, las migraciones forzadas conllevan un alto riesgo que afronta quien las sufre. Riesgo que se traduce en muchos casos en precariedad vital. Como mantendremos en este artículo, los actuales procesos de fuga y movilidad laboral de los jóvenes se integran en el más amplio proceso de precariedad laboral, en la que se encuentran inmersos desde hace más de dos décadas. La fuga y la movilidad se entienden como un episodio ulterior de dicha precariedad, ya estructural, que se suma a la larga lista de precariedades que han ido caracterizando los recorridos laborales de gran parte de la juventud.

La repetición de las imágenes de nuestros jóvenes migrantes en los medios de comunicación ha convertido la fuga en una especie de icono de la 
cuestión juvenil actual, pero, desgraciadamente, a la reiteración mediática no le ha acompañado un análisis profundo sobre los procesos de fondo en los que se enmarca la denominada fuga de cerebros. Como veremos a continuación, en las escasas publicaciones en el campo de la sociología que han abordado el tema abunda un enfoque culturalista, que toca muy superficialmente los factores estructurales que impulsan la fuga y no capta los profundos intereses empresariales que dinamizan la movilidad laboral. La falta de estos elementos da como resultado investigaciones muy improvisadas y débiles conceptualmente, donde no se aprecian los procesos profundos que condicionan la movilidad laboral forzada de los jóvenes en España. El objetivo de este artículo es precisamente aportar algunos elementos teóricos y conceptuales que permitan avanzar la investigación sociológica sobre la fuga de cerebros y las migraciones laborales de los jóvenes universitarios.

El episodio de fuga de cerebros que se ha vivido en España se ha identificado con esa imagen de multitud de jóvenes que abandonaban el país por falta de oportunidades. Este episodio coyuntural, ceñido a la crisis, es el que ha abierto las primeras planas de los periódicos al tema de la fuga. Sin embargo, esa coyuntura no se entiende si la fuga no se enclava en transformaciones de gran calado en las concepciones y representaciones laborales que actúan desde momentos previos a la actual crisis. Sin dichas transformaciones, no se entienden los procesos de movilidad laboral que estamos viviendo. La fuga de cerebros ya existía con anterioridad a la crisis y, cuando esta ya no se refleje en los macroindicadores, seguirá existiendo. Antes del 2007, los jóvenes cualificados ya salían de España empujados por las dinámicas de globalización del capital y las empresas. Lo que la crisis ha permitido es una intensificación de la movilidad y un robustecimiento de las legitimaciones empresariales que la preconizan.

Por ello, independientemente de la resolución de la crisis, la fuga es ya una experiencia vivida para los jóvenes, una experiencia que ensancha los límites de las exigencias laborales que han de estar dispuestos a aceptar en el mercado de trabajo global. Independientemente de que sigan yéndose o de que retornen tras la crisis, la fuga y movilidad es ya una marca indeleble en la actual generación móvil y un buen analizador de las tendencias próximas que los jóvenes vivirán en sus cursos vitales y laborales. La fuga se ha convertido en una categoría interpretativa clave de la juventud universitaria actual.

De cara a avanzar en el análisis de estos procesos de fuga y movilidad, dedicaremos un primer apartado (1) a examinar el lugar que la lógica del 
capital humano ocupa en los episodios de fuga y movilidad. Esta lógica construye una conceptualización determinada del trabajo y se acompaña de otros conceptos, como los de empleabilidad o empresario de sí mismo (Foucault, 2007) que son el sustrato ideológico de los actuales procesos de movilidad.

En el segundo apartado (2), nos centraremos en el concepto de movilidad internacional y presentaremos algunos de los argumentos que la legitiman tal y como se expresan en el discurso experto.

\section{CAPITAL HUMANO Y TRABAJADOR EMPRESARIO DE SÍ MISMO: CONCEPTOS QUE ENMARCAN LA FUGA Y MOVILIDAD ACTUAL DE LOS JÓVENES}

La lógica del trabajo entendido como capital humano ha dado pasos de gigante en estos últimos años en todos los países capitalistas. Entre los titulados universitarios, puede decirse que está ya plenamente extendida. En paralelo a los procesos de mercantilización de la educación, el avance de la teoría del capital humano entre los universitarios ha sido constante en las dos últimas décadas (Hirtt, 2003; Laval, 2004; Sevilla, 2010). Esta teoría y su expresión en la esfera del trabajo vehiculan una representación determinada del mundo social. Dicha representación conlleva una forma particular de entender el trabajo y el ser humano, que es la expresión de determinados intereses y concepciones. No es una forma cualquiera o la más eficaz, neutra o sin repercusiones negativas para nadie. Al contrario, es un enfoque interesado, tras el cual se encuentran las visiones empresariales, que salen favorecidas. Este enfoque ensalza una imagen de sociedad entendida como un conjunto de individuos emprendedores que compite entre sí y consigo mismos por su propio interés y donde cada uno es responsable de su fracaso o éxito. Los costes asociados a esta forma de interpretar la realidad social son importantes y, en concreto, se traducen en riesgo y trayectorias inciertas que veremos al final de este apartado. En definitiva, concebirse a sí mismo como capital humano tiene importantes repercusiones sobre la vida personal y laboral.

Si se quieren hacer investigaciones profundas sobre las trayectorias y la movilidad de los jóvenes se hace necesario considerar la actual hegemonía y significado de esta interpretación del capital humano que rige los destinos de los jóvenes actuales. Por ello, iniciaremos este apartado buscando los orígenes e intereses que están detrás de la concepción del capital hu- 
mano y, posteriormente, veremos cómo se ha materializado y convertido en hegemónico a través de la continua concreción de prácticas, normas e instituciones que construyen un nuevo modelo de racionalidad dominante en la esfera laboral y educativa. Nos detendremos particularmente en describir algunos rasgos de este proceso en la Unión Europea (Hirtt, 2013).

\subsection{Del trabajador entendido como empresario de sí mismo}

En la indagación crítica sobre el impacto social de la lógica del capital humano, ocupa un lugar privilegiado el curso que Michel Foucault (2007) pronunció en 1979 en el Collège de France.Allí enclava en el desarrollo del neoliberalismo la teoría del capital humano, desarrolla su significado y presagia el profundo impacto histórico que este enfoque tendría. En la interpretación de Foucault, el neoliberalismo reformula las concepciones de la economía y el trabajo desde los años 30 del siglo xx. En contraste con la tradición liberal, que concebía la economía como un proceso en el que se conjugaban capital, trabajo y producción, los neoliberales la redefinen para concebirla como un comportamiento y su racionalidad interna (la racionalidad maximizadora de los agentes). En este giro de los «nuevos clásicos», que tendría luego su mayor expresión en la escuela de Chicago, la economía pasa a ser una ciencia del comportamiento humano: la ciencia de la "programación estratégica de la actividad de los individuos» (Foucault, 2007: 261).

De este modo, Gary Becker (1967), miembro destacado de la corriente neoliberal americana, reinterpreta también el lugar del trabajo en la economía. Frente a los enfoques clásicos, que entendían el trabajo como esfuerzo de trabajo medido en unidades de tiempo en el marco de la producción, los «nuevos clásicos» reinterpretan el trabajo como conducta económica. Es decir, el nuevo análisis económico del trabajo ha de plantearse cómo el trabajador utiliza los recursos de los que dispone, en una conducta guiada por el cálculo y la racionalidad. La racionalidad del bomo economicus llevada al extremo.

El impacto que esta reformulación del trabajo tiene sobre las relaciones sociales y laborales es profundo. El neoliberalismo pasa a concebir el salario como un ingreso que proviene del rendimiento de un capital: el capital humano del trabajador. Desde este punto de vista (y aquí está una de las claves del futuro impacto de esta teoría), el salario es una renta de capital y no una remuneración. Así, Becker (1967) define el capital humano como 
conjunto de factores físicos y psicológicos que permiten extraer un rendimiento económico. El capital humano es una máquina que producirá un flujo de renta. Esta manera de entender el trabajo es lo que lleva a Foucault a prefigurar cambios profundos en las relaciones sociales: del asalariado que vende su fuerza de trabajo en el mercado pasamos, con los planteamientos neoliberales de la teoría del capital humano, al trabajador entendido como «empresario para sí mismo» (Foucault, 2007: 264).

Transformado en empresario para sí mismo, el trabajador ha de dedicarse personalmente a mejorar su capital humano, de su acumulación y de la mejora de su composición tanto física como psicológica y formativa. La formación se concibe así como una inversión guiada por la tasa de rendimiento futuro. Los jóvenes que estudian son inversores, pues invierten en su capital en pos de rentas futuras mayores. Estudiar es un comportamiento y una decisión. No serán ya trabajadores sino capitalistas propietarios de su capital humano. Serán empresarios que provean un servicio a otros empresarios que lo comprarán.

Esta concepción del trabajo sitúa la lógica empresarial en el centro de las relaciones sociales. El capital humano define una economía compuesta por trabajadores que se comportan como unidades-empresa y no como colectivos de asalariados. La doctrina de Becker conlleva la generalización de la forma empresa, sobre la cual gravitará el proyecto neoliberal posterior: una sociedad integrada bajo el principio rector de la forma empresa, que se infiltra en todas las relaciones sociales. Una «economía generalizada» (Passet, 2012).

En línea con estos planteamientos genealógicos de Foucault, André Gorz (2001) sigue la pista a los impactos sociales recientes de la lógica del capital humano y analiza sus repercusiones en la organización actual del trabajo en la economía del conocimiento. Gorz señala que la expansión del trabajo inmaterial reclama cada vez más a los trabajadores competencias empresariales. La empresa en la era del conocimiento es ya plenamente una empresa compuesta por empresarios de sí mismos y lo ejemplifica con las palabras del director de recursos humanos de Daimler Chrysler, que considera que:

Los colaboradores de la empresa son parte de su capital [...] Su motivación, su saber hacer, su flexibilidad, su capacidad de innovación, su preocupación por los deseos del cliente constituyen la materia prima de los servicios innovadores [...] Su trabajo no se mide ya en horas, sino sobre la base de los resultados alcanzados y de la calidad [...] son emprendedores (Gorz, 2001: 62). 
Esta «transferencia de competencias empresariales» hacia los asalariados diluye paulatinamente el conflicto capital-trabajo. Evidentemente, si todos somos una empresa no hay lugar para los viejos antagonismos entre obreros y empresarios.

Por añadidura, en los actuales mercados de trabajo del conocimiento, donde abundan los servicios de atención directa a la persona, se impone la capacidad de autoproducirse como actividad. En los empleos comerciales, de enseñanza, de consultoría, de terapia o en las actividades artísticas, deportivas, es fundamental «saber vender y venderse». Esta capacidad de producirse a sí mismo, tan en consonancia con el cuidado del propio capital humano, se extiende a la par que lo hace el volumen de estos empleos, donde la presencia de los jóvenes es abundante. En estas profesiones, los individuos asumen la responsabilidad de gestionar su capital humano, su carrera, incluida su capacidad de movilidad. En definitiva, han de incrementar su empleabilidad de cara a ser competitivos y administrarse como una empresa. En muchas de estas ocupaciones, cada vez más se mezcla la esfera del capital humano y la esfera de la vida personal, con lo cual el construirse como empresa repercute en diferentes procesos vitales como «la sexualidad, el matrimonio, la procreación, la salud, la belleza, la identidad, los conocimientos, las relaciones, las ideas» (Gorz, 2001: 65). Obliga a reinventarse, readaptarse y a sobreexplotarse. Este trabajo de adaptación al cambio continuo ejerce una dilatación extrema en la esfera del yo, forzado a decidir sobre la opción más racional para maximizar el capital humano.

Sería extenso detenerse en ello, pero en paralelo a este trabajo permanente sobre sí mismo y sobre la mejora de la capacidad de decisión y del autogobierno se ha desarrollado todo un campo de técnicas de autoayuda estrechamente emparentadas con el mundo de la empresa -desarrollo personal, mindfulness, programación neurolingüística, coaching-. Estas técnicas tratan de incrementar el rendimiento, la autonomía y la movilidad del personal, sobre todo directivo, a través una mejora en la gestión de las emociones, en la asertividad, en la autovaloración (Stevens, 2007), en la forma de conducirse en la vida (Ampudia de Haro, 2006; Landa y Marengo, 2011; Papalini, 2013). Micki McGee (2005) ha asociado la eclosión de los libros de autoayuda en Estados Unidos con la nueva forma de esclavitud que supone fabricarse la propia empleabilidad o reforzar la autoestima de cara a la ansiedad por permanecer en el trabajo. Estos gadgets psicológicos son también utilizados por los directivos como autoanestesia en todos los procesos de despido y decisiones dramáticas o estresantes relacionadas con el competitivo mundo del trabajo. 


\subsection{Jóvenes de la Unión Europea, cautivos del capital humano y la empleabilidad}

En estrecha relación con el concepto de capital humano, se ha difundido también el de empleabilidad, en realidad es su corolario, pero ofrece algunos matices importantes sobre los que nos detendremos. La empleabilidad supone que el propio individuo buscador de empleo se hace cargo de las competencias necesarias para incrementar su atractivo en el mercado de trabajo y que elige aquellas que son las correctas en términos de acrecentar su competitividad. En estas dos últimas décadas, en paralelo a la empresarialización de la educación, hemos presenciado el ascenso de la idea de competencias. Frente al enfoque tradicional basado en la educación y la cualificación, ha pasado a ser hegemónico concebir la educación en términos de formación y competencias (Hirtt, 2003). En el enfoque tradicional, el papel del Estado en la educación de los ciudadanos tenía un peso determinante, pero la llegada de las competencias desvela que el actor preponderante es la empresa. De ella surgen las directrices que gobiernan el sector de la formación en este periodo. De lo que se trata ahora es de crear un modelo de organización de los saberes basado en dotar a los estudiantes de una serie de competencias que reclama el mundo empresarial.

Sobre este proceso de desregulación de la educación y sobre el papel de las competencias en ello se ha escrito mucho en los últimos años (Alonso et al., 2009). La gran parte de clasificaciones sobre las competencias recogen la importancia de la transversalidad y del elemento cognitivo en ellas. La Comisión Europea (2009), por ejemplo, incluye las siguientes competencias clave: comunicación en lengua materna, comunicación en lenguas extranjeras, competencia matemática y competencias básicas en ciencias y tecnologías, competencia numérica, aprender a aprender, competencias sociales y cívicas, espíritu de iniciativa y de empresa, sensibilidad y expresión culturales. Este informe de la Comisión Europea no oculta su participación en el giro empresarial y mercantil al que asistimos y en su subtítulo anuncia que persigue «adaptar la oferta de competencias a las necesidades del mercado de trabajo». Es clara la transición del centro escolar como servicio público, que define sus fines, al centro escolar como proveedor comercial de enseñanza definida por el mercado.

En estos momentos de cambio rápido, las empresas prescinden de saberes concretos y apuestan por saberes empresariales abstractos, aplicables, para adecuar sus necesidades en el binomio escuela-empresa. Por ello preconizan una formación flexible, que facilite la adaptabilidad de los jóvenes 
y su reconvertibilidad de acuerdo a los usos y necesidades dictaminadas por el mercado de trabajo y los intereses cambiantes de las empresas y su lógica de competitividad. Esta, se traspone, así, automáticamente al curso de vida formativo de los jóvenes: lo que se reclama son jóvenes competentes y competitivos a lo largo de su vida.

La pregunta que nos planteamos es cuáles serán las repercusiones a largo plazo de este enfoque tan interrelacionado con las trayectorias de movilidad de los jóvenes. Como en tantos otros campos, y bajo el empuje de los intereses a corto plazo del mundo empresarial, se toman decisiones sin conocer el impacto futuro que estas puedan causar en las relaciones sociales. El debate y las investigaciones sobre el capitalismo académico y la mercantilización de la educación es extenso y muy rico en enseñanzas, por ahora bastante desoídas (Slaughter y Larry, 1997; Montlibert, 2004; McHenry, 2010; Sotiris, 2013).

En este caso, y ciñéndonos a las implicaciones personales que para los jóvenes puede tener este enfoque de las competencias, hay que señalar la coincidencia amplia de los autores anteriores en el proceso de individualización que desencadena y en la desocialización consiguiente. El individuo en formación trabaja para sí de cara a la mayor eficacia de la empresa. Emprende supuestas estrategias y decisiones, cuando realmente la entidad de referencia en el nuevo orden global del mercado es la empresa que marca la pauta de las decisiones. Con lo cual el individuo se convierte en un actor de la incertidumbre global improgramable en la que le sume el deseo de las empresas. Este individuo es sistemáticamente sometido al veredicto experto empresarial acerca de la pertinencia de sus elecciones formativa y sus carencias. Igualmente se valorarán tus resultados o el valor añadido que tu capital humano aporta a la empresa y al accionista. Es a ellos a quien debe rendir cuentas el capital humano. Esta persecución del rendimiento se despliega en las prácticas de auditoría permanente y evaluación a la que se ven abocados estos sujetos auditados del capital humano. Evaluación, por otra parte en cascada, que enfrenta competitivamente a los pares y presiona a los subordinados para obtener así mejores evaluaciones.

Esta flexibilidad puede traer, quizá, beneficios a los jóvenes en términos de libertad de opción educativa y de rentabilizar y diferenciar su capital humano, pero la pérdida de control sobre la definición de las competencias que se les reclaman hace que los horizontes de vida y de formación sean cada vez más imprevisibles (Roggero, 2005; Hirtt, 2013). Van desde el estrés de la elección educativa o la incertidumbre sobre su valorización una vez acabados los estudios, hasta los procesos de responsabilización, 
intensificación y precarización en el trabajo y otros riesgos y repercusiones en el curso de vida. Si se ignoran estos condicionantes en los recorridos de movilidad de los jóvenes, se hace imposible investigar la movilidad laboral actual de los jóvenes. Antes que aventureros cosmopolitas, los jóvenes son capital humano, mano de obra.

\section{DE LA CUNA A LA FRONTERA: LA MOVILIDAD COMO CONDICIÓN DE LAS VIDAS PRECARIAS}

La noción de empleabilidad, además de estar vinculada con las competencias, es entendida en un sentido amplio como cuidado del propio capital humano, trasladando así la carga de la creación de empleo a los jóvenes: ya no se trata simplemente de insertarse en un mercado laboral externo a ellos y a ellas, sino que se les transmite que son unos actores más del mercado y deben crear las condiciones para el empleo. En esta nueva configuración, los jóvenes asumen la obligación de aumentar la empleabilidad, afrontando costes considerables, que les pueden ocasionar perjuicios importantes en las trayectorias vitales (y en ocasiones las huellas permanecerán durante mucho tiempo). De esta forma hemos asistido en estos años a la expansión desaforada de las prácticas no remuneradas para titulados, el crecimiento de postgrados y todo tipo de cursos de especialización (muchos de los cuales ofrecen también prácticas no remuneradas como principal atractivo), la extensión de la flexibilidad (trabajo por proyectos, horarios cambiantes, etc.) en el seno de «malos» empleos, todo ello para conseguir algo de experiencia laboral, etc. Una de las estrategias que más repercusión simbólica ha tenido entre las personas jóvenes es la movilidad internacional. Al margen de las prácticas concretas, la salida del país ha ganado proyección, puesto que invoca elementos que han sido mitificados en los discursos sobre la empleabilidad: idiomas, actitudes, contactos, etc.

En este contexto, la llamada «fuga de cerebros», la movilidad de personas jóvenes cualificadas, se incorpora a las exigencias de la empleabilidad, perfilando una nueva etapa en la precarización vital. Los retos de la globalización se transfieren de las empresas hacia los jóvenes: se apela a la competencia global para incidir en la necesidad de «prepararse» y ser «competitivos», adquiriendo cualificaciones, aptitudes y actitudes que ofrezcan una «ventaja comparativa» (idiomas, disponibilidad a la movilidad...). Así, cuando en los discursos empresariales se habla de movilidad internacional, los titulados universitarios son un objetivo estratégico: conforman un precaria- 
do cualificado que puede engrasar a muy bajo coste los circuitos de una economía financiarizada y cada vez más global (Brown et al., 2011, Standing, 2011).

En los años que van desde el inicio de la crisis, ha crecido la cantidad de personas jóvenes tituladas que han salido del país a buscarse la vida. Aunque los datos no son precisos debido a la escasez de fuentes fiables y a la falta de voluntad política para cuantificar el fenómeno, sabemos que pueden ser varios cientos de miles los jóvenes que han marchado a otros países en busca de empleo (González-Ferrer, 2013). Este suceso puede suponer una marca biográfica considerable en la trayectoria vital. Para «hacerse mayores» ya no basta con formarse, buscar empleo, encontrar pareja e hipotecarse, ahora hay que invertir en uno mismo, tener espíritu cosmopolita, internacionalizarse y, finalmente, saltar al vacío sin red. Esta salida de los jóvenes no se produce en un espacio social neutro, sino que se materializa sobre estratificaciones previas, vinculadas fundamentalmente con la clase social. Además, el contexto discursivo está, como hemos apuntado, plagado mensajes contradictorios, pero en él tienen gran peso los discursos de agentes poderosos (grandes bancos y empresas, gobiernos y grupos mediáticos), que vinculan la movilidad internacional con cuestiones presentadas como positivas: modernidad, dinamismo, emprendimiento, etc.

2.1. El cosmopolitismo como nueva forma de determinismo social: crítica a los planteamientos culturalistas sobre la juventud

Al hablar de enfoques culturalistas nos referimos a interpretaciones que explican el cambio social desde el punto de vista exclusivo de la transformación de los valores, dejando de lado otros factores, como la clase social (France y Haddon, 2014). Actualmente está tomando vigor la perspectiva del cosmopolitismo. Se trata de una etiqueta que invisibiliza las situaciones de desigualdad y vulnerabilidad, dándoles una pátina a medio camino entre las explicaciones culturales y psicológicas, con un eco funcionalista. Esta perspectiva omite o ignora algunos argumentos importantes, que llevarían a una lectura más compleja de la fuga de cerebros, poniéndola en relación con los procesos de precarización y con las dinámicas y discursos empresariales, entre otros factores. Por otra parte, la perspectiva cosmopolita trata a la juventud como un grupo homogéneo, sin distinguir las múltiples situaciones de las personas jóvenes que salen del país y asimilando la juventud a una especie de estadio universal y unívoco al margen de los con- 
textos concretos. Consideramos, por tanto, que esta perspectiva tiene vínculos profundos con una concepción funcionalista de la juventud y de los jóvenes, proponiendo unas nociones más normativas que explicativas. El recurso al cosmopolitismo moviliza un subtexto que resta aspereza a la ruptura biográfica que conlleva la fuga. Este argumento configura una idea de tipo moral (Nowicka y Rovisco, 2009), antes que una descripción comprensiva de la realidad, sugiriendo una proposición normativa sobre la juventud: ésta ha de ser moderna, abierta al contacto, etc. Vamos a repasar brevemente algunos de los argumentos que se esgrimen para defender esta perspectiva cosmopolita. Como veremos, estas ideas entroncan plenamente con los discursos empresariales sobre la circulación del talento y las credenciales que son valoradas por las empresas de reclutamiento de fuerza de trabajo (Brown et al., 2011).

Para hacerlo seguiremos principalmente dos informes que han sido publicados recientemente, uno de ellos por el Instituto de la Juventud (coordinado por Navarrete, 2014) y el otro por la Fundación Encuentro (2013), ambos de interés por estar publicados por entidades con una trayectoria en los estudios sobre los jóvenes y la sociedad y un reconocimiento público (sobre todo en el caso del Injuve) que hace que tengan un impacto en la creación y difusión de discursos mediáticos y políticos. El estudio del Injuve, titulado «La emigración de los jóvenes españoles en el contexto de la crisis» elabora una descripción de la magnitud y composición de los flujos de jóvenes hacia el extranjero y completa esta descripción con un análisis de una encuesta y de entrevistas en profundidad. El documento de la Fundación Encuentro se enmarca en el conjunto del llamado Informe España 2013, unos informes anuales que publica esta fundación y que ofrecen un diagnóstico de la situación socioeconómica. En concreto, nos centramos en el capítulo dedicado a los jóvenes y titulado «Los jóvenes hoy: aprender a tomar decisiones en un entorno enmarañado».

Los defensores de esta perspectiva parten de la premisa de que los jóvenes forman parte de una "generación cosmopolita» (Navarrete, 2014:86). Efectivamente, en el intento de comprensión de la sociedad contemporánea y sus transformaciones, es importante considerar la dinámica de difusión y recepción de símbolos y signos, que podrían modificar la percepción y las identidades que los sujetos tenemos del mundo. Sin embargo, Beck (2006) reconocía que no hay datos suficientes para afirmar la existencia de una "generación global». Tomar como eje los valores compartidos por esta generación supone olvidar el contexto en el que la misma se ha de desarrollar. La «hipótesis cosmopolita» difumina la vinculación de los 
jóvenes con los contextos específicos, lo que diluye la influencia de condicionantes externos en el proceso de toma de decisiones. Así, resulta chocante que en la defensa de la "hipótesis cosmopolita» no se contraste el hecho de que el periodo de crisis coincida con una mayor salida del país de los jóvenes titulados, algo que el propio informe del Injuve reconoce: «el inicio de la crisis económica cuando comienza a incrementarse exponencialmente el porcentaje de jóvenes que se desplazan al exterior» (Navarrete, 2014: 109). A pesar de la evidente relación entre crisis y fuga, el enfoque cosmopolita no ofrece explicaciones satisfactorias para este repunte vinculado a una coyuntura adversa: se olvida de esto y se decanta por los factores de tipo cultural. Las motivaciones para salir de esta generación se nos presentan como algo relacionado con la «oportunidad de vivir nuevas experiencias, conocer diferentes culturas, la posibilidad de conocer gente nueva y ampliar el círculo social» (Navarrete, 2014: 104). Esta lectura pasa por alto, por ejemplo, que si el factor principal hubiera sido un cambio en los valores, sería más probable haber observado esta movilidad «cosmopolita» en la época de bonanza económica, cuando los recursos (individuales y familiares), las becas, etc., eran más boyantes. Tomando las nociones de Beck (2006), es necesario distinguir entre un cosmopolitismo emancipatorio y otro despótico. Cuando una decisión como la de salir del país está tan fuertemente condicionada es difícil hablar de «aventura», en el sentido romántico. Se trata más bien de una especie de prueba, una barrera, que hay que superar después de encontrar un muro (el de la precarización) en la sociedad de origen. Cuando existen estas constricciones el cosmopolitismo pierde fuerza explicativa, puesto que aunque recoge un rasgo ciertamente presente en las generaciones jóvenes (mayor inclinación y deseos por viajar y conocer otras realidades), no se puede afirmar que dicho rasgo sea central en el actual fenómeno de fuga de cerebros.

Poner en el centro los «nuevos» valores implica olvidar el desempleo masivo, la extensión de los malos empleos y la precariedad que viven los y las jóvenes. En la misma línea que los discursos provenientes del ámbito de los recursos humanos, la salida del país se interpreta como una forma selfentrepreneurship: una estrategia que aumentaría el capital cultural («conocer diferentes culturas») y el capital social («ampliar el círculo social»). Pero, ¿cuál es el peaje para una generación que ve como le mueven el suelo de los pies: reformas laborales infinitas, endurecimiento del acceso a prestaciones y pensiones, recortes de becas, etc.? Parece que más que un precio a pagar, los jóvenes se estuvieran beneficiando de una «inversión» 
que rentabilizarán en algún momento posterior de sus vidas. Esta rentabilización futura podría complicarse si como suponemos, la condición precaria, corporeizada en los jóvenes, se convierte en la norma o, en otras palabras, si la juventud como estatus se convierte en el destino generalizado en las sociedades avanzadas.

Otro elemento que no se suele considerar en las investigaciones con este enfoque cosmopolita es el que se refiere a los antecedentes (background) de clase de las personas que protagonizan la salida. El capital social, económico y cultural (el nivel de estudios de padres y madres, la renta familiar, el tipo de instituciones en las que se han formado, etc.) podrían tener una influencia nada despreciable en las trayectorias y en las experiencias vividas y, por tanto, en la configuración del discurso sobre la salida del país (Kennedy, 2009). La malla de seguridad familiar, las experiencias previas (formación en idiomas, colonias de verano, etc.) e incluso los primeros pasos en la estrategia laboral en el extranjero (empezar, por ejemplo, con un máster que incluya prácticas), proporcionan unas condiciones de partida para unas trayectorias que, con mayor probabilidad, posibilitarán la consecución de empleos aceptables sin tener que pasar por empleos de baja cualificación y remuneración (bares, hoteles, etc.).

Cuando la explicación cosmopolita se encuentra con aspectos difíciles de encajar en el plano de los valores, echa mano de los procesos cognitivos para decirnos que los jóvenes tienen una visión «contradictoria» de la realidad. Por ejemplo, el informe del Injuve indica la existencia de percepciones que consideran la salida al extranjero una «alternativa forzada por las circunstancias y que restringe sus opciones» (Navarrete, 2014: 118). Esta emergencia en el discurso de constricciones ajenas al sujeto que poco tienen que ver con los valores cosmopolitas, es explicada recurriendo a una argumentación de difícil interpretación, que desvía las causas de esta percepción hacia los mecanismos de cognición:

Esto puede parecer contradictorio, pero desde el análisis parece más una evaluación pragmática positiva en la dimensión económica y profesional, que presenta elementos de baja compatibilidad con la evaluación en su dimensión emocional y relacional (Navarrete, 2014: 118).

Por su parte, el informe de la Fundación Encuentro coincide en lo fundamental con la perspectiva del informe del Injuve. Aporta una argumentación que bascula sobre el cambio en los valores y, en líneas generales, simplifica la interpretación de la salida del país de los jóvenes, interpretación que también se apoya en el cosmopolitismo.Así, al hecho de que una 
mayoría de jóvenes afirmen que salen por «necesidad», la Fundación Encuentro plantea una interpretación tautológica y autocontenida: «se trata de un complejo cultural que actúa como un doble vínculo: es necesario porque es posible, es posible porque es necesario» (Fundación Encuentro, 2013: 163). Como vemos, recurre a lo cultural y coloca necesidad y posibilidad en un mismo plano, lo que trivializa la necesidad en tanto a constricción en el proceso de toma de decisiones. Una alternativa a estos enrevesados enunciados del Injuve y la Fundación Encuentro sería comprobar qué está sucediendo en el contexto para que los y las jóvenes digan que tienen «necesidad» de salir e incluso que se sienten «forzados». Pretender que nuestros jóvenes formen "parte de ese amplio colectivo cosmopolita que aparece en prácticamente todos los países» (Fundación Encuentro, 2013: 165) es una atribución que confunde más que explica: desaparecen los condicionantes de unas decisiones que no se toman en las mejores condiciones.

Este enfoque que venimos comentando ve en la diáspora «la construcción de una sociedad cosmopolita» (Fundación Encuentro, 2013: 161). En la línea de la psicología positiva asociada a la literatura managerial (Ehrenreich, 2011), rápidamente nos avisan de que la necesidad puede ser también una oportunidad. Ubican el fenómeno de la fuga en un supuestamente ventajoso proceso de integración global de las sociedades y, por tanto, de sus habitantes, entre los cuales los más jóvenes, debido a su «espíritu aventurero», serían más proclives al contacto con otros países. Para llevar la mirada hacia lo que pueda haber de positivo, se recurre a veces a argumentos ciertamente extravagantes: «de manera creciente, los españoles contribuyen a crear diversidad étnica y cultural en otras sociedades» (Fundación Encuentro, 2013: 163). Al margen de lo que hagan o de cómo les vaya, al menos queda el consuelo de que dan color al mundo.

Tratando de redondear este contexto en el que la movilidad parece ser algo tan cotidiano como neutro, desde la perspectiva cosmopolita hacen un dibujo global en el que saltar de país en país e incluso iniciar proyectos de vida cada dos por tres no presentan dificultades destacables: «La casi totalidad del planeta Tierra se ha convertido en un único territorio, mejor o peor comunicado, en el que las personas, en particular las personas jóvenes, se desplazan con mayor o menor rapidez, cambian de residencia y se instalan con creciente facilidad en un nuevo territorio para desarrollar un proyecto de vida propio» (Fundación Encuentro, 2013: 164).

Ante este panorama de movilidad desenfrenada y «complejidad cultural» el diagnóstico parece claro: «El fenómeno puede interpretarse de una for- 
ma más precisa como «cosmopolitismo»y visualizarse como un estilo de vida que el conjunto de todos los inmigrantes y emigrantes comparte» (Fundación Encuentro, 2013: 165). Se trata, según los autores del informe, de un «estilo de vida», es decir, algo voluntariamente adoptado. Recordemos que según el DRAE, estilo es una forma de comportamiento y una moda. Esta consideración de la migración como parte de un «estilo de vida» cuenta en la literatura académica con una cierta producción en el seno de lo que en inglés se conoce como «lifestyle migration» (Benson y O'Reilly, 2009). Estas formas de conceptualizar la migración

include the good life, escape from past individual and community histories, and the opportunity for self-realisation, strategies post migration often include the re-negotiation of the work-life balance, maintaining quality of life and freedom from prior constraints (Benson y O'Reilly, 2009: 610).

En el centro de esta concepción está la autorrealización y no la migración laboral forzada por el desempleo; de hecho en los textos sobre lifestyle migration se suele dejar fuera la migración laboral. Desde nuestro punto de vista esta forma de conceptualizar la movilidad puede ser adecuada para algunos perfiles, pero en absoluto para la gente joven precaria que ha tenido que salir del país forzada por la ausencia de expectativas laborales. En estas condiciones la «autorrealización» no pasa por la mejora del empleo o por el contacto intercultural, sino muy probablemente por tener alguna posibilidad de conseguir ingresos económicos y posibilidad de una vida autónoma.

Más allá de las motivaciones y de los condicionantes, otro aspecto que se pasa por alto desde la opción cosmopolita son las condiciones de vida de los jóvenes en los países de destino. Son varios los trabajos que muestran que la movilidad laboral exterior de los jóvenes implica incertidumbre (sobre todo en los primeros momentos) y un incremento de la vulnerabilidad, puesto que disminuyen los apoyos (sobre todo los informales) con los que cuentan, así como que esta situación se puede alargar debido a la baja remuneración y malas condiciones de los empleos a los que generalmente acceden (Chaloff y Lemaitre, 2009). Los argumentos cosmopolitas restan importancia a esta cuestión, presentando este proceso como una cuestión sencilla y vinculada de nuevo con un estilo de vida que se adquiere en ausencia de condicionantes. Así, el informe de la Fundación Encuentro sugiere la existencia de un «estilo de vida cosmopolita» en los lugares de destino, al cual «se adhiere una parte cada vez mayor de personas jóvenes, adoptando valores pragmáticos y minimalistas lejos del contexto fami- 
liar» (Fundación Encuentro, 2013: 165). La forma de vida asociada a la condición precaria deviene en una especie de minimalismo virtuoso, fruto de la maduración que conlleva estar «lejos del contexto familiar».

En definitiva, el enfoque cosmopolita ofrece una explicación descontextualizada y más bien normativa que descriptiva. Se trata de una serie de argumentos que toman como base cambios en las identidades que darían forma a una supuesta generación cosmopolita, la cual circula con facilidad por un mundo socialmente plano. Este enfoque viene como anillo al dedo a algunas de las más recientes embestidas del neoliberalismo, como por ejemplo la flexiseguridad, escenario que implicaría una redefinición de la movilidad, naturalizando la precariedad e incorporando la «transición» como un elemento constante, no sólo de los mercados de trabajo, sino también de las vidas de las personas (Morini, 2014). En un plano profundo, el cosmopolitismo refuerza los discursos sobre la creatividad, el talento y el emprendimiento (Peck, 2005; Calhoun, 2002). Unos discursos que parecen esforzarse en presentarnos la salida de los jóvenes como una más de las «deseables» inversiones en sí mismos que estos han de hacer para incrementar su capital humano.

\section{CONCLUSIONES: DE LA JUVENTUD A LOS Y LAS JÓVENES. LA NECESIDAD DE NUEVOS ENFOQUES EN EL ESTUDIO DE LA MOVILIDAD EN LA ERA DE LA PRECARIZACIÓN}

En estas conclusiones, querríamos recoger dos ideas que se desprenden de las páginas anteriores y que consideramos importantes en el actual panorama de las transiciones-trayectorias-movilidades juveniles. La primera se refiere a la necesidad de seguir profundizando en los planteamientos teóricos sobre las trayectorias juveniles. Los enfoques culturalistas y funcionalistas de la juventud que hemos criticado en el apartado anterior, tienen muchas dificultades para interpretar los complejos procesos de movilidad de los jóvenes. En el panorama actual de la sociología de la juventud en España están muy extendidos estos enfoques y sería necesario impulsar nuevas líneas teóricas y aproximaciones empíricas, que completen la respuesta limitada propuesta por el culturalismo a las movilidades laborales de los jóvenes españoles.

En este sentido, siguen teniendo vigencia las referencias hoy clásicas de autores como Richard Sennett (2000) y Zygmunt Bauman (2013), con sus conceptos de riesgo, crisis del valor de la experiencia y liquidez. Igualmen- 
te, persiste la validez de la crítica de Bourdieu $(1979,2000)$ a los planteamientos culturalistas en lo que respecta a la juventud. En el capítulo «La juventud es solo una palabra», Bourdieu (2000) adelantó la idea de que no tiene sentido estudiar la cuestión juvenil como una especie de sustancia universal, sino que para analizar la esfera de los jóvenes, la sociología ha de guiarse por las lógicas y luchas sociales en torno a la reproducción, luchas que se dan entre grupos sociales diferenciados. Tras la palabra juventud se esconden universos sociales y lógicas distintas que solo pueden explicarse a partir de la evolución estructural del campo en cuestión. Martín Criado (1998) o Conde (2013) ofrecen ejemplos de estos planteamientos para el caso de los jóvenes en España.

En el momento actual y en el campo laboral de los jóvenes, algunos de los conceptos, y sus evoluciones recientes, propuestos en estas líneas pueden servir para avanzar en la comprensión de la fuga y de la movilidad laboral contemporánea de los jóvenes. Es necesario partir de los cambios que conllevan la expansión de la lógica del capital humano, de la empleabilidad o de una determinada concepción empresarializada de la movilidad laboral si se quieren comprender los efectos perjudiciales que éstas están trayendo hoy a los jóvenes. Aunque no nos hemos detenido en este artículo en dichos efectos, estos jóvenes afectados por las movilidades laborales que estamos presenciando están bajo una situación de riesgo creciente. Los universitarios móviles, en diferentes grados, quedan solos ante los riesgos de la doctrina de la empleabilidad. Sus recorridos transmiten soledad e incertidumbre. Este proceso abierto al riesgo que supone la movilidad es asumido individualmente, sin apenas recursos sociales que den seguridad al proceso, sin apenas información o ayudas. En estos procesos de activación laboral a los universitarios, la responsabilización los convierte en sujetos productivos con alto rendimiento potencial, pero también sujetos a procesos vitales corrosivos e impactos duraderos en sus cursos vitales.

Dardot y Laval (2009) han hablado a este respecto de clínica del neosujeto para describir los problemas y síntomas provocados por la actual ruptura en los marcos sociales tradicionales que dan lugar a este nuevo sujeto reclamado por el capital humano y la empleabilidad. Un sujeto para el que parece no haber límites, para el que todo parece posible, pero nada es seguro. 


\section{BIBLIOGRAFÍA}

Alonso, L. E.; Fernández, C. y Nyssen, J. (2009): El debate sobre las competencias, una investigación cualitativa en torno a la educación superior $y$ el mercado de trabajo en España, Madrid, ANECA.

Ampudia De Haro, F. (2006): "Administrar el yo: literatura de autoayuda y gestión del comportamiento y los afectos», Revista Española de Investigaciones Sociológicas, 113, pp. 49-72.

Bauman, Z. (2013): Sobre la educación en un mundo líquido, Madrid, Paidós.

Beck, U. (2007): Cosmopolitan vision, Cambridge, Polity Press.

BECKER, G. S. (1967): Human capital: a theoretical and empirical analysis with special reference to education, New York, National Bureau of Economic Research.

Benson, M.Y O'ReILLY, K. (2009): «Migration and the search for a better way of life: a critical exploration of lifestyle migration", The Sociological Review, 57-4, pp. 608-625.

Bourdieu, P. (1979): «Les trois états du capital culturel», Actes de la Recherche en Sciences Sociales, 30, pp. 3-6.

BOuRdieu, P. (2000): Cuestiones de sociología, Madrid, Istmo.

Brown, P.; LAUder, H. y Ashton, D. (2011): The global auction. Broken promises of education, jobs, and incomes, New York, Oxford University Press.

Calhoun, C. (2002): «The class consciousness of frequent travelers: towards a critique of actually existing cosmpolitism», en Vertovec, S. y COHEN, R. (ed.), Conceiving cosmopolitanism. Theory, context and practice, New York, Oxford University Press. (pp. 86-109).

Chaloff, J. y Lemaitre, G. (2009): «Managing Highly- Skilled Labour Migration: A Comparative Analysis of Migration Policies and Challenges in OECD Countries», OECD Social, Employment and Migration Working Papers, 79, OECD Publishing (http://dx.doi.org/10.1787/225505346577).

Comisión EuRopea (2009): Nouvelles compétences pour de nouveaux emplois. Anticiper les compétences requises et adapter l'offre de compétences aux besoins du marché du travail, Luxembourg, Office des publications de l'Union Européenne.

CONDE, F. (2013): «Crisis y transformación del contrato de integración social de los jóvenes», Revista Jóvenes y Más, 5 (http://jovenesymas.fad.es).

DaRdot, P. y LAVAL, СH. (2009) La nouvelle raison du monde, La Découverte, Paris. 
EHRENREICH, B. (2011): Sonríe o muere. La trampa del pensamiento positivo, Madrid, Editorial Turner.

Foucault, M. (2007): Nacimiento de la biopolítica, Buenos Aires, FCE.

France, A. y Haddon, E. (2014): «Exploring the epistemological fallacy: subjectivity and class in the lives of young people», Young, 22(4), pp. 305321.

FundaCión EnCUENTRo (2013): Informe España 2013, Madrid, Fundación Encuentro.

GonZÁlez-Ferrer,A. (2013): «La nueva emigración española. Lo que sabemos y lo que no», Zoom Político, 18, pp. 1-18.

Gorz A. (2001): «La personne devient une entreprise. Note sur le travail de production de soi», Revue du MAUSs, 2001/2, 18, pp. 61-66.

HirtT, N. (2003): Los nuevos amos de la escuela. El negocio de la enseñan$z a$, Madrid, Ed. Minor Network.

HirTt, N. (2013): «Educar y formar bajo la dictadura del mercado de trabajo», Con-ciencia Social:Anuario de Didáctica de la Geografía, la Historia $y$ las Ciencias sociales, 17, pp. 39-54.

Kennedy, P. (2009): "The middle class cosmopolitan journey: the life trajectories and transnational affiliations of skilled Eu migrants in Manchester», en Nowicka, M. y Rovisco, M., Cosmopolitanism in practice, Farnham, Ashgate (pp. 19-36).

LANDA, M. I. y Marengo, L. (2011): «El cuerpo del trabajo en el capitalismo flexible: lógicas empresariales de gestión de energías y emociones», Cuadernos de Relaciones Laborales, 29-1, pp. 177-199.

Laval, CH. (2004): La escuela no es una empresa, Barcelona: Paidós.

Mcgee, M. (2005): Self-Help, Inc.: Makeover Culture in American Life, New York, Oxford University Press.

Martín Criado, E. (1998): Producir la juventud, Madrid, Istmo.

MChenry, L. (2010): «La mercantilización del saber: influencias mercantiles en la búsqueda del conocimiento», Pasajes: Revista de Pensamiento Contemporáneo, 33, pp. 31-41.

Montlibert, С . (2004): Savoir à vendre. L'enseignement supérieur et la recherche en danger, Paris, Raisons d'Agir.

Morini, C. (2014): Por amor o a la fuerza. Feminización del trabajo y biopolítica del cuerpo, Madrid,Traficantes de Sueños.

Navarrete, L. (2014): La emigración de los jóvenes españoles en el contexto de la crisis. Análisis y datos de un fenómeno difícil de cuantificar, Madrid,: Observatorio de la Juventud de España. 
Nowicka, M. y Rovisco, M. (2009): «Making sense of cosmopolitism», en Nowicka, M. y Rovisco, M., Cosmopolitanism in practice, Farnham, Ashgate. (pp. 1-16).

PAPAlini, V. (2013): «Recetas para sobrevivir a las exigencias del neocapitalismo», Nueva Sociedad, 245, pp. 163-177.

PASSET, R. (2012): Las grandes representaciones del mundo y la economía a lo largo de la bistoria. Madrid-Buenos Aires, Ed. Clave Intelectual y Eudeba.

PECK, J. (2005): «Struggling with the creative class», International Journal of Urban and Regional Research, 29-4, pp. 740-770.

Roggero, G. (2005): Intelligenze fuggitive, Roma, Manifestolibri.

SENNETT, R. (2000): La corrosión del carácter, Barcelona, Anagrama.

Sevilla, C. (2010): La fábrica del conocimiento. La universidad-empresa en la producción flexible, Madrid, El Viejo Topo.

Slaughter, S. y Larry L. (1997): Academic Capitalism. Politics, Policies and the Eentrepreneurial University, Baltimore, The Johns Hopkins University Press.

SoTIRIs, P (2013): «Teorizando la universidad-empresa. Preguntas abiertas y algunas posibles respuestas», en Fernández, J., Urbán, M. y Sevilla, C. (coords.) De la nueva miseria, Madrid,Akal (pp. 43-66).

Standing, G. (2011): The Precariat: the new dangerous class. London, Bloomsbury.

Stevens, H. (2007): «L'entreprise de soi», La Revue Nouvelle, 10, pp. 52-59. 